\title{
EL PODER DE LOS SÍMBOLOS Identidad colectiva y movimiento etnolingüístico en el País Vasco
}

\author{
Benjamín Tejerina \\ Universidad del País Vasco \\ E-mail: cjptemob@lg.ehu.es
}

\begin{abstract}
RESUMEN
La idea que me gustaría desarrollar es que cualquier intento de explicación de lo que sucede hoy en el País Vasco con el proceso de recuperación de la lengua sólo puede ser entendido si lo relacionamos con el proceso de construcción de la identidad colectiva vasca. En la cristalización de esta vinculación creciente entre lengua e identidad, el movimiento etnolingüístico ha desempeñado un papel central. Trataré de desarrollar mi argumento en cinco apartados. Primero, expondré las diferentes aportaciones teóricas sobre el proceso de construcción de la identidad colectiva y los enfoques dominantes en el análisis de la movilización social. Segundo, repasaré los antecedentes históricos más recientes sobre la identidad colectiva vasca y los contextos en los que se van transformando sus contenidos. Tercero, presentaré las consecuencias para la lengua y la identidad colectiva vasca del movimiento de recuperación lingüística de los años sesenta y setenta. Cuarto, analizaré la influencia de los cambios políticos de los ochenta y la progresiva institucionalización de la identidad colectiva vasca sobre el movimiento y la situación lingüística. Quinto, estudiaré las transformaciones que han tenido lugar en el movimiento de recuperación lingüística en los últimos años como resultado de los cambios experimentados en la sociedad vasca.
\end{abstract}

\section{INTRODUCCIÓN}

Domingo 23 de marzo de 1997. Un corredor con un testigo cruza la línea de llegada en El Arenal de Bilbao. Tras él lo hacen varios miles de personas que han acompañado el testigo a lo largo de los últimos kilómetros por las calles de Bilbao. Terminaba así la décima edición de Korrika, que desde su inicio el

\section{Reis}


viernes 14 de marzo en Arantzazu había recorrido 2.150 kilómetros por pueblos y ciudades del País Vasco. Según los organizadores de esta carrera de relevos, la Coordinadora de Alfabetización y Euskaldunización (AEK), más de 600.000 personas habían tomado parte en esta edición, superando la participación de actos anteriores en favor de la recuperación del euskera.

Lo sorprendente de Korrika no es que el número de participantes aumente de edición en edición, sino que su número supere al de vascohablantes. Dado que la cantidad de vascos monolingües es del 0,5 por $100(12.400)$ del total de la población del País Vascoo la práctica totalidad de los que conocen euskera es bilingüe y puede comunicarse perfectamente en castellano o francés. ¿Por qué empeñarse en recuperar una lengua (euskera), con la consiguiente inversión de recursos humanos y económicos, cuando todos podemos comunicarnos en otra lengua (castellano o francés)? ¿Qué sentido tiene que un grupo humano haya decidido en un determinado momento recuperar una lengua que era conocida por menos del 20 por 100 de la población vasca y utilizada cotidianamente por un porcentaje menor de personas?

La idea que me gustaría defender es que cualquier intento de explicación de lo que sucede hoy en el País Vasco con el proceso de recuperación de la lengua sólo puede ser entendido si lo relacionamos con el proceso de construcción de la identidad colectiva vasca. En la cristalización de esta vinculación creciente entre lengua e identidad, el movimiento etnolingüístico ha desempeñado un papel central, aunque junto a él han intervenido otros actores sociales y agentes políticos.

La relevancia del movimiento etnolingüístico fue mayor en los difíciles momentos del régimen de Franco (1939-1975), en el que toda actividad en euskera estaba perseguida, al igual que cualquier acto de reivindicación o expresión de la identidad nacional vasca. Sin embargo, es con posterioridad a este período cuando se extiende, hasta llegar a ser dominante en la sociedad vasca $^{2}$, la idea de que la afirmación de la identidad colectiva vasca requiere la recuperación de la lengua autóctona: el euskera.

En el contexto político de la transición a la democracia y de la posterior consolidación de una estructura política descentralizada (Comunidades Autónomas), tanto los procesos de construcción de la identidad colectiva como de recuperación de la lengua experimentan profundas transformaciones, al igual que ocurre con el movimiento etnolingüístico. El objetivo de este artículo es analizar la contribución de la movilización etnolingüística al proceso de construcción de la identidad colectiva vasca, y cómo dicha definición de la identidad colectiva está impulsando la recuperación lingüística que el País Vasco viene experimentando en las últimas décadas.

1 Según la II Encuesta Sociolingüística de Euskal Herria, realizada en 1996, sólo 534.100 personas (el 22 por 100) mayores de 15 años podían ser consideradas bilingües con una adecuada capacidad de comunicarse en euskera.

2 Dominante no quiere decir que dentro de la sociedad vasca no existan sectores sociales importantes que rechazan su necesidad. 
Trataré de desarrollar mi argumento en cinco apartados. Primero, expondré las diferentes aportaciones teóricas sobre el proceso de construcción de la identidad colectiva y los enfoques dominantes en el análisis de la movilización social. Segundo, repasaré los antecedentes históricos más recientes sobre la identidad colectiva vasca y los contextos en los que se van transformando sus contenidos. Tercero, presentaré las consecuencias para la lengua y la identidad colectiva vasca del movimiento de recuperación lingüística durante los años sesenta y setenta. Cuarto, analizaré la influencia de los cambios políticos de los ochenta y la progresiva institucionalización de la identidad colectiva vasca sobre el movimiento y la situación lingüística. Quinto, estudiaré las transformaciones que han tenido lugar en el movimiento de recuperación lingüística en los últimos años como resultado de los cambios experimentados en la sociedad vasca ${ }^{3}$. Pero antes de entrar en el análisis de lo que ha sucedido históricamente en el caso vasco, reflexionaré sobre los conceptos de identidad colectiva y movimientos sociales, así como sobre los tres enfoques dominantes en el estudio de la acción colectiva.

\section{LOS ENFOQUES TEÓRICOS SOBRE LA ACCIÓN COLECTIVA Y LOS MOVIMIENTOS SOCIALES}

Un movimiento social es el resultado de una acción colectiva constituida por el conjunto de interacciones formales e informales entre una pluralidad de individuos, colectivos y grupos organizados que comparten entre sí, en mayor o menor grado, un sentimiento de identidad colectiva al entrar en conflicto con otros agentes sociales o políticos, por la apropiación (de), participación (en) o transformación de las relaciones de poder o las metas a alcanzar mediante la movilización de determinados sectores de la sociedad ${ }^{4}$.

${ }^{3}$ El ejemplo del movimiento etnolingüístico me parece altamente relevante para la investigación sobre la acción colectiva y la movilización social por varias razones. Primera, porque en este caso concreto aparecen todas las dimensiones analíticas que se han apuntado en distintos enfoques para explicar el origen y desarrollo de los movimientos sociales. Segunda, porque aunque este movimiento se solapa, en ocasiones, con el movimiento nacionalista vasco, sus actividades y movilizaciones pueden ser separadas con una cierta facilidad en la mayor parte de los casos; la existencia de vasos comunicantes entre ambos movimientos sociales no impide su consideración de manera separada. Tercera, el largo proceso de germinación y el prolongado desarrollo del movimiento etnolingüístico nos permite estudiar el efecto que sobre él han ido teniendo las progresivas transformaciones en la estructura política. Cuarta, el objeto de la movilización etnolingüística resulta fácilmente operacionalizable tanto si se mide en términos de institucionalización como si se hace atendiendo a las prácticas y actitudes de los actores sociales.

${ }^{4}$ Dada la versatilidad de los fenómenos en torno a los que aparecen movimientos sociales y las transformaciones ecológicas e históricas de sus manifestaciones, una definición esencialista debe descartarse. En su lugar, prefiero utilizar una definición de carácter analítico que señale algunos de sus posibles componentes y, sobre todo, se centre en el resultado de la movilización social. Para una discusión sobre las definiciones de movimiento social puede consultarse Diani (1992). 
En el caso que estoy tratando, el movimiento etnolingüístico participa en la definición y realización de una identidad colectiva cuyo elemento central es la lengua que habla un grupo determinado. La pretensión fundamental de este movimiento social es que los habitantes de un territorio plurilingüe constituyan su definición grupal en torno al elemento lengua (el euskera) como símbolo de adscripción al grupo de pertenencia o al que se desea pertenecer, y que esta definición sirva tanto para aquellos que la poseen como para aquellos que desconociéndola se identifican afectivamente con ella.

Para el análisis de los movimientos sociales se han elaborado diferentes enfoques teóricos. Tres son los más utilizados en la actualidad: la teoría de la movilización de recursos, la teoría de la identidad colectiva y el proceso político.

1) La teoría de la movilización de recursos se centra en el proceso mediante el que un grupo asegura el control de los recursos que necesita para llevar a cabo una acción colectiva. Las cuestiones fundamentales que se plantea son el control de los recursos disponibles antes de dar paso a la movilización, el proceso por el que el grupo selecciona los recursos y los dirige hacia el objetivo de cambio social, y el nivel de contribución por parte de las personas ajenas al grupo en lo referente al incremento del abanico de recursos disponibles (Jenkins, 1983: 532-533).

A pesar de las dificultades de delimitar claramente el concepto de recurso y de la ausencia de acuerdo sobre los tipos de recursos que resultan más significativos, existe un gran número de evidencias empíricas sobre la relevancia para el análisis de los movimientos sociales de, al menos, tres aspectos:

a) En los momentos iniciales de la movilización son importantes los recursos disponibles entre los potenciales beneficiarios de la acción colectiva, pero también lo son los recursos facilitados por otros grupos y asociaciones en forma de apoyos y colaboración, personal cualificado, infraestructura e incentivos.

b) En el ámbito de la gestión de los recursos (estrategia y tácticas), la paulatina sustitución de una parte de las formas más clásicas de organización en los movimientos sociales con liderazgo autóctono, personal voluntario, afiliación extensiva, recursos de los beneficiarios directos y acciones basadas en la participación masiva por organizaciones más profesionalizadas con liderazgo externo, personal remunerado a tiempo completo, afiliación reducida o inexistente, recursos de las comunidades conscientes y acciones que "hablan en nombre» del grupo agraviado sin requerir su participación (Zald y McCarthy, 1987).

c) En las relaciones con el conjunto de la sociedad, las organizaciones de los movimientos sociales encuentran la infraestructura necesaria para su movilización. Los aspectos que pueden utilizar incluyen los medios de comunicación de masas, el nivel de prosperidad, el grado de acceso a los centros institucionales, las redes de relaciones preexistentes o la estructura ocupacional (McCarthy y Zald, 1977: 20). 
2) Un segundo enfoque es la teoría de la identidad colectiva. Hoy resulta fácil encontrarnos con artículos que tienen como objeto el análisis de la identidad colectiva en los movimientos sociales. Pero una simple consulta a la base de datos Sociofile confirma que el primer artículo que aparece en esta relación está fechado en $1982^{5}$. Hay trabajos anteriores como los de Pizzorno o Touraine, pero quien mejor ha sabido desarrollar el concepto de identidad colectiva es, en mi opinión, Melucci. Partiendo de sus aportaciones, me gustaría reflexionar brevemente sobre cómo entiendo yo el concepto de identidad colectiva.

Con el término «identidad colectiva» me refiero a un sentimiento de pertenencia compartido por los miembros de un grupo o por varios grupos, mediante el que es interpretada y definida la realidad, orientando las acciones de los que participan de dicho sentimiento. La identidad colectiva puede cristalizar y objetivarse, pero está sometida en todo momento a la posibilidad de cambio y reelaboración. La identidad colectiva no es algo puramente simbólico -que pertenece al mundo de los símbolos y de las interpretaciones-, también pertenece al mundo de las prácticas sociales ${ }^{6}$.

La identidad colectiva entendida de esta manera implica un conjunto de elementos y procesos sobre los que merece la pena que nos detengamos:

a) Un aspecto relevante de toda identidad es su dimensión dinámica, es decir, el proceso constante de creación y reproducción (Codol, 1981; Guiot, 1977; Taboada-Leonetti, 1981; Kastersztein, 1981; Erikson, 1966; Tajfel, 1974). Como ha señalado C. F. Graumann, «la identidad es menos un estado final que un proceso dinámico de construcción y reconstrucción».

b) La pertenencia de los individuos a una sociedad o grupo social, al igual que su exclusión de ellos, quedan reguladas por la identidad colectiva (Gurruchaga, 1985: 14-15). La existencia de un nosotros, de una comunidad de individuos que comparten una pauta cultural común, un referente comunitario, evita la necesidad de recurrir a instancias ajenas a sus miembros para alcanzar su reconocimiento social, lo que pone de manifiesto el carácter simbólico de la identidad colectiva (Cohen, 1985: 118).

c) La cuestión central no radica en identificar aquellos rasgos objetivos e inmutables sobre los que descansa la identidad colectiva (Kohn, 1984; Smith, 1991). El problema de la identidad de los grupos debe plantearse desde la

La base de datos Sociofile contiene una gran cantidad de artículos de sociología publicados entre 1974 y 1997 . Entre estas fechas sólo aparecen 36 referencias relativas a la identidad colectiva y los movimientos sociales; 31 de ellas han aparecido con posterioridad a 1990, y sólo 5 entre 1982 y 1989. El primer artículo que aparece es de Richard Weiner, «Collective identity formation and social movements», publicado en Psychology and Social Theory, 3 (primavera-verano 1982), pp. 13-23.

${ }_{6}^{6}$ Esta definición es similar a la utilizada por Melucci cuando afirma que la identidad colectiva es el proceso de construcción de un sistema de acción, una definición interactiva y compartida producida por un conjunto de individuos y grupos relativa a las orientaciones de su acción y el campo de oportunidades y limitaciones en el que dicha acción tiene lugar (Melucci, 1996: 70). 
conciencia o representación que sus miembros tienen de sí mismos o la representación que un determinado observador puede tener de un grupo concreto ${ }^{7}$.

d) Aquellos elementos de carácter simbólico capaces de dar significación social a las acciones de los individuos y convertir la significación en algo compartido constituyen lo más central de todo grupo social, aquello sobre lo que descansa la especificidad de toda sociedad, el centro simbólico ordenador de la acción (Shils, 1961).

e) Los atributos comunes en los que se fundamenta la identidad de un grupo social son convertidos por los actores sociales en categorías de adscripción e identificación. A través de los atributos comunes, sus miembros se autoidentifican y son identificados por otros. Son categorías que tienen la particularidad de generar diferencialidad frente a otros grupos sociales, estableciendo unos límites o fronteras entre los grupos. La persistencia de los grupos sociales depende del mantenimiento de dichos límites (Barth, 1976: 16).

3) En tercer lugar tenemos el enfoque del contexto político, al que han contribuido autores como D. McAdam, H. Kriesi o S. Tarrow, entre otros, y cuyo concepto central es el de oportunidad política. S. Tarrow ha definido la estructura de oportunidad política como el conjunto de dimensiones del entorno político que proporciona incentivos para que se produzca una acción colectiva, afectando sus expectativas de éxito o fracaso. Este enfoque enfatiza, sobre todo, la movilización de los recursos externos disponibles a un grupo determinado. Con este concepto se pretende ayudar a entender por qué los movimientos sociales obtienen temporalmente incentivos frente a las élites o las autoridades $\mathrm{y}$, después, los pierden rápidamente a pesar de sus mejores esfuerzos (Tarrow, 1994: 85).

Tarrow diferencia dos tipos de elementos en la estructura de oportunidad política, unos más estables y otros que responden más fácilmente a procesos de cambio. Entre los primeros, se subraya la importancia de la fortaleza del Estado, medida a través del grado de centralización/descentralización de su estructura administrativa, y la posibilidad de reprimir o facilitar (control social) la acción colectiva. Mientras un Estado centralizado tiende a concentrar las demandas de los actores colectivos en la cima del sistema político, los Estados descentralizados proporcionan a los movimientos sociales un gran número de puntos de acceso para la reivindicación de sus objetivos en la base del sistema institucional. En referencia a las formas de represión y control social, el Estado puede optar por una estrategia represiva, o por la utilización de otros medios de control social como la legitimación y la institucionalización de la acción colectiva.

${ }^{7}$ Me refiero, claro está, al tipo de representación y no a su contenido. Los contenidos de las representaciones sobre grupos humanos varían [pueden variar] en función de las características socioestructurales de los miembros del grupo. Sobre la cuestión de las relaciones entre lengua e identidad en las comunidades bilingües pueden consultarse los estudios realizados por Miguel Siguán para el CIS. 
Entre los aspectos cambiantes de la estructura política que proporcionan oportunidades y recursos a los movimientos sociales, $S$. Tarrow enumera cuatro: el grado de apertura a la participación, que repercute en la acción colectiva; los cambios en las alianzas dominantes, sobre todo cuando se producen alianzas inestables; la existencia y disponibilidad de aliados influyentes; y la división entre élites, que se manifiesta en conflictos dentro de y entre las élites. Estas cuatro dimensiones más coyunturales de la estructura política son otros tantos factores que pueden extender y difundir las oportunidades de ciertos grupos para llevar a cabo una movilización colectiva.

Utilizaré estos tres enfoques sobre la acción colectiva como tres conjuntos de factores (recursos materiales y humanos, espectos simbólicos e identitarios y oportunidades del contexto político) para tratar de comprender la movilización etnolingüística y sus resultados ${ }^{8}$.

\section{MOVILIZACIÓN ETNOLINGÜÍSTICA E IDENTIDAD COLECTIVA VASCA: ANTECEDENTES HISTÓRICOS RECIENTES}

De acuerdo con lingüistas e historiadores, el euskera ha sido la lengua hablada durante mucho tiempo en el País Vasco y más allá de sus actuales límites. Sin embargo, el resultado de los procesos de cambio económico, político y cultural de los últimos siglos ha ido erosionando la situación del euskera tanto en extensión como en espacios de utilización. Este proceso de debilitamiento lingüístico se acentúa con el proceso de modernización a partir del siglo XIX ${ }^{9}$. Hacia 1876, la situación del euskera despierta el interés de un grupo de intelectuales que van a desarrollar un proyecto de recuperación cultural, en el que la lengua se identifica como el factor más destacable de la conciencia colectiva vasca. Autores como Becerro de Bengoa o Arturo Campión definen a la lengua vasca como núcleo central de la nacionalidad vasca.

La gran contribución de A. Campión y del movimiento de renacimiento cultural que se inicia con la Asociación Euskara de Navarra es doble: por un lado, no se limita a denunciar la situación de la lengua, sino que emprende

${ }^{8}$ Para la realización de este trabajo he utilizado material procedente de tres investigaciones desarrolladas desde finales de los ochenta. Los antecedentes históricos son una reelaboración y actualización de una investigación publicada por el CIS con el título de Nacionalismo y lengua.Los procesos de cambio lingüistico en el País Vasco. Una primera aproximación a la dimensión interna del movimiento, a las organizaciones, activistas, discurso y estrategia del movimiento de recuperación lingüística puede encontrarse en Sociedad civil, protesta y movimientos sociales en el País Vasco (Tejerina, Fernández Sobrado y Aierdi, 1995). La parte más sustancial de este artículo procede de las doce entrevistas personales y dos reuniones de grupo realizadas con activistas de las organizaciones más relevantes, así como con altos responsables de los organismos públicos encargados de la planificación y normalización lingüística en el País Vasco.

9 Una detallada exposición de estos procesos históricos puede encontrarse en Euskaltzaindia (1977), Tejerina (1992) y Sarasola (1976). 
una reflexión teórica de los factores tanto externos como internos que han ido configurando dicha situación; por otro, en una dimensión más práctica, impulsa la organización de toda una serie de actividades socioculturales que pretenden romper la tendencia dominante al cambio lingüístico (sustitución del euskera por el castellano), a través de la toma de conciencia de la realidad de la lengua entre los distintos sectores sociales del País Vasco. En esta dirección, adquirieron gran importancia las producciones literarias, los relatos históricos, etc., que se multiplicaron a lo largo del siglo XIX, a medio camino entre la historia real y la inventada o recreada. Cuando no existen trabajos históricos que cubran la ausencia de datos, cuando nos encontramos que en determinadas épocas históricas hay grandes lagunas que nos impiden su reconstrucción fidedigna, la novela y la creación literaria llenan ese vacío a través de las leyendas noveladas o los relatos mitológicos (Hobsbawn y Ranger, 1983; Aranzadi, 1981; Juaristi, 1987).

En este contexto de cambio social, S. Arana (1865-1903) trató de dar una nueva proyección política a la identidad vasca definiéndola en términos nacionales. Para lo que nos interesa, es de la máxima importancia detenernos en la significación social y la dimensión política de la lengua en el discurso de S. Arana, y cómo aparecen en este discurso una serie de elementos que se convertirán en el capital simbólico a utilizar por ulteriores formulaciones nacionalistas de la identidad colectiva.

Para S. Arana, la nacionalidad vasca descansa en cinco elementos: la raza, la lengua, el gobierno y las leyes, el carácter y las costumbres, y la personalidad histórica. No todos tienen el mismo peso o importancia, estableciéndose una jerarquía entre ellos. El elemento fundamental de la nacionalidad vasca descansa en un hecho incontestable: la raza.

Independientemente de la voluntad de los individuos, la raza es el elemento diferencial que señala al pueblo vasco como una nación distinta. La forma de permanecer en esta diferencialidad racial es preservar su particularidad lingüística; en este sentido, la lengua es, al mismo tiempo, mecanismo de integración, de cohesión social, y mecanismo de diferenciación étnica (Arana, 1965: 1713).

El interés del euskera no descansa tanto en sus valores intrínsecos como en la importancia que tiene para la raza. La utilización y conservación de la lengua será preservadora de la pureza racial (Arana, 1965: 404). Por otro lado, junto con la lengua viene el sentimiento patriótico, puesto que patria y lengua van siempre inesticablemente unidas (Solozábal, 1975: 357).

Este carácter secundario que $S$. Arana atribuye a la lengua, supeditándola al desarrollo del sentimiento nacionalista, condicionará la tarea emprendida para recuperar y extender el conocimiento y uso del euskera. A pesar de esta limitación, tanto Arana como sus seguidores llevarán a cabo programas para fomentar la enseñanza del euskera en la escuela y fuera de ella, así como un número importante de «estudios euskarológicos» (Corcuera, 1979: 396-397).

Las primeras décadas del siglo XX van a representar la expansión y consoli- 
dación de dichas ideas. Junto al desarrollo del Partido Nacionalista Vasco (PNV/EAJ), se van creando una serie de organizaciones que aglutinan a amplios sectores sociales en torno al movimiento nacionalista, llegando a configurar un entramado social con una vida interna muy dinámica, una «microsociedad». Sobre este entramado social, que intenta dar respuesta a todas las etapas de la vida y todas las actividades de la sociedad tradicional, se sustenta la movilización del nacionalismo vasco. Entre los sectores de la sociedad vasca que participan en este proceso, sobresale el papel desempeñado por grupos provenientes de los sectores eclesiásticos. De entre ellos destaca P. Ariztimuño (Aitzol), quien llevará a cabo una adecuación de las ideas sabinianas, en un momento que permite ir limando los desajustes y consumar la evolución de la ideología nacionalista.

Para P. Ariztimuño, el valor del idioma descansa en la capacidad de conformar la mentalidad colectiva, más que en su valor intrínseco como medio de comunicación o como agente de transmisión de conocimientos científicos. Si el idioma es capaz de conformar la conciencia colectiva de un pueblo, será el complemento adecuado de la raza. Entre ambos, las peculiaridades históricas de un pueblo pueden ser mantenidas. Por tanto, la raza es, desde cualquier punto de vista, el elemento de diferencialidad principal, pero gracias a que la lengua se convierte en su soporte (Elorza, 1978: 318).

Para este autor, el objeto principal de un idioma no es su dimensión comunicativa, ni su mayor o menor riqueza expresiva; lo fundamental es la capacidad de integración y cohesión entre los que lo conocen y utilizan: «La finalidad primordial de una lengua no es difundir los elevados enunciados de la ciencia, ni revelar las filigranas estéticas de las creaciones artísticas. El objeto, fundamentalísimo, de un idioma es el que éste sirva de lazo de relación y expresión de un pueblo, de una colectividad étnica. Por eso, son los idiomas algo tan íntimamente ligado con los grupos raciales, como lo es, guardadas las proporciones debidas, el alma para el cuerpo. El idioma es el alma, el espíritu, el valor esencial más íntimo, lo que caracteriza más intrínsecamente la conciencia de un pueblo» (Elorza, 1978: 319).

\section{TIEMPOS DE EXCEPCIONALIDAD, CAMBIOS POLÍTICOS Y RENACIMIENTO CULTURAL}

En los primeros años de la posguerra, como consecuencia de la derrota del nacionalismo en la Guerra Civil, el régimen franquista generaliza una represión sistemática de todo símbolo nacionalista. La escuela y la calle se convierten en los ámbitos de máxima represión de la lengua. La imposibilidad de la utilización de la lengua en los escenarios sociales de carácter público impone el repliegue del euskera a los espacios de la vida privada y familiar. El ámbito de la intimidad se convertirá en el lugar privilegiado de su utilización. La familia, como único lugar en el que la presencia del euskera es posible, verá reforzado 
su papel de mecanismo fundamental de conservación y transmisión de la lengua, aunque sin llegar a ser completamente autónomo. La transmisión intergeneracional de la lengua en el seno familiar es el único espacio al que la represión no tiene posibilidad de acceder directamente. Sin embargo, en algunos casos, esta transmisión se ve interrumpida como consecuencia de la interiorización de la represión en el mundo familiar.

A la represión que se ejercía sobre la lengua en los ámbitos oficiales y en los espacios públicos, se le unió un proceso de inmigración de gran importancia demográfica en las décadas de los años cincuenta y sesenta. La consecuencia de estos factores fue una disminución del uso de la lengua, tanto en espacios geográficos como en ámbitos sociales. La presión política que se ejerció sobre la lengua durante el franquismo impulsó su desaparición o retroceso en los límites e, incluso, en el corazón del país, el abandono del espacio público y su refugio en la privacidad familiar, la pérdida de su conocimiento y transmisión, y la imposibilidad de su utilización en la mayor parte de las situaciones cotidianas de interacción social. Paradójicamente, la disminución en el uso del euskera produjo la toma de conciencia de su pérdida. La autoconciencia de esta pérdida vivida traumáticamente vino a reforzar la dimensión simbólica de la lengua.

La situación de la literatura vasca en los primeros años de la posguerra es la de una literatura inexistente. En palabras de Joxé Azurmendi, el «escritor vasco es el artista inesperado que escribe en una lengua que no existe y es, sin embargo, entendido, por los que tienen que entenderle» (Torrealday, 1977: 51). De hecho, tendrá que llegar el año 1949 para ver publicado el primer libro en euskera desde el final de la guerra civil (un poema religioso de Salbatore Mitxelena), y sólo cinco años más tarde comenzará a tomar cuerpo una tenue recuperación de la actividad cultural. Durante estos años se lleva a cabo, en el silencio de los seminarios y de otras instituciones eclesiásticas, una tarea de cultivo del euskera y de la literatura que impulsará, posteriormente, un movimiento de recuperación cultural de gran significación social.

Este proceso de recuperación lingüística y cultural coincide en el tiempo con una redefinición de la conciencia nacional. Las profundas transformaciones de carácter socioeconómico que se habían producido y se estaban acentuando en estos años planteaban al nacionalismo un serio problema. El nacionalismo tradicional se adecuaba, no sin dificultad, a la nueva realidad que, como consecuencia de los cambios producidos en la sociedad vasca, estaba emergiendo. Las dos primeras décadas de franquismo habían supuesto la generalización de un sentimiento agónico del nacionalismo vasco, cuyo rasgo más visible era el retroceso de la lengua. En el contexto de los cambios que la estructura social había experimentado como consecuencia de la industrialización, la urbanización y la llegada de inmigrantes, los jóvenes nacionalistas se planteaban dos tareas inminentes: dar una respuesta ante la inactividad de los mayores, inmersos todavía en la frustración por la pérdida de la guerra y la derrota del nacionalismo; y emprender una redefinición del nacionalismo vasco capaz de adecuarse a la nueva realidad de la sociedad vasca. 
Frente al primer problema, la nueva generación planteará un cambio de actitud: ante la inactividad de los mayores se impone la acción. Pero, en relación al segundo problema, esta acción debe estar orientada por una reformulación del nacionalismo tradicional. Ante la imposibilidad creciente de mantener el confesionalismo y los fundamentos racistas sabinianos, propondrán otro elemento "objetivo» que pueda garantizar la peculiaridad y la diferencialidad de la sociedad vasca y que sirva, al mismo tiempo, como elemento aglutinador capaz de generar cohesión social. En este contexto, la lengua, el euskera, va apareciendo como el elemento etnocultural más significativo $\mathrm{y}$, con el paso del tiempo, llegará a desempeñar un papel fundamental en la redefinición del nacionalismo vasco.

Esta idea de que la lengua constituye el soporte «objetivo» de la nación vasca no es algo que esté completamente claro desde el principio, sino que se llegará a ella al descartar otros elementos «objetivos» sobre los que se había hecho descansar la particularidad de lo vasco. Paulatinamente se toma conciencia de que la nacionalidad, la diferencialidad del pueblo vasco, no puede recaer en lo biológico (raza). Será la influencia de Federico Krutwig y su obra Vasconia. Estudio dialéctico de una nacionalidad (1963) la que proporcione los elementos necesarios para que ETA realice la formulación ideológica que fundamente su redefinición del nacionalismo vasco (Letamendía, 1975; López, 1976).

El sentimiento agónico con que es percibida la situación de la lengua, sobre todo la disminución de su uso, y la necesidad de dar una contestación a la incapacidad de reacción que se había extendido entre la generación de sus mayores impulsará, entre los militantes de ETA [Euskadi ta Askatasuna-Euskadi y Libertad], una actitud regeneracionista. Su objetivo más inmediato se centrará en la recuperación de la lengua vasca, ya que "el euskera es la quintaesencia de Euskadi: mientras el euskera viva, vivirá Euskadi»; de forma que "el día en que el euskera haya dejado de ser lengua hablada, el pueblo vasco habrá muerto; y en pocos años, los sucesores de los actuales vascos serán simplemente españoles o franceses» (Jáuregui, 1981: 160).

En la formulación de ETA, la lengua adquiere preeminencia como componente básico de la identidad colectiva vasca sobre cualquier otro elemento. La lengua se convierte en el correlato empírico de la identidad diferencial del pueblo vasco; sin embargo, lo relevante es el sentimiento de pertenencia a una comunidad, el sentimiento patriótico que vehicula dicha identidad nacional. Lo importante es que en la medida que se recupera la lengua se extiende también la identidad colectiva nacional vasca, pero, al mismo tiempo, dicha identidad adquirirá mayor difusión si se potencian las actividades en favor de la recuperación de la lengua. En realidad, estamos ante dos dimensiones, complementarias, de un mismo problema. Por ello, no tiene sentido emprender una tarea de recuperación lingüística que no vaya acompañada de la extensión de la identidad colectiva nacional. Ahora bien, para ETA, el problema del euskera y de la identidad nacional del pueblo vasco se enmarca en un contexto más 
amplio. Contexto en el que es la opresión política que se ejerce sobre el pueblo vasco la que está impidiendo tanto su desarrollo como su expresión. La falta de un marco político en el que lengua e identidad colectiva se puedan expresar es lo que encorseta y genera su situación actual. Sólo será posible alcanzar estos objetivos en una estructura política que garantice su persistencia como lengua e identidad nacionales, es decir, mediante la consecución de una Euskadi políticamente independiente (Letamendía, 1975; López, 1977; Garmendia, 1979; Jáuregui, 1981; Ibarra, 1989). En esta situación, la recuperación de la lengua y, con ella, la identidad nacional quedan supeditadas a la consecución del objetivo político del autogobierno del pueblo vasco.

La reformulación teórica del discurso nacionalista que se produce en la década de los sesenta tiene una doble influencia sobre la situación de la lengua. Por un lado, la lengua se convertirá en el elemento de mayor significación social para la construcción de la diferencialidad de la identidad colectiva vasca, como correlato empírico de la existencia de una comunidad diferenciada. La adhesión afectiva a la lengua refuerza su dimensión participativa, como símbolo de pertenencia a la comunidad. Por otro lado, esta adhesión afectiva a la lengua, como símbolo de pertenencia a un grupo social que posee una identidad colectiva diferenciada, mueve a los individuos que nunca la han poseído o que la han perdido a aprenderla. Cómo y en qué circunstancias fue ello posible, así como el alcance de dichos procesos, serán las cuestiones que trataremos de aclarar en los siguientes apartados. La primera cuestión a abordar es: ¿por qué los individuos de una determinada colectividad se plantean la necesidad de recuperar su lengua en un momento de retroceso acelerado?

\section{IDENTIDAD Y RECURSOS PARA LA MOVILIZACIÓN ETNOLINGÜÍSTICA}

La lengua en el País Vasco ha venido perdiendo importancia como medio de comunicación (vertiente comunicativa) desde hace bastantes decenios. La lengua ha ido retrocediendo territorialmente frente al avance de otras lenguas, disminuyendo el porcentaje de vascohablantes sobre el total de la población, desapareciendo o perdiéndose su uso en determinados espacios sociales, etc. Estos rasgos de la situación social de la lengua nos permiten plantear una hipótesis: la lengua vasca ha venido experimentando un descenso en su uso como medio de comunicación. Durante el régimen de Franco, la lengua se ve sometida a una represión y a una sobrepresión política que acentúan este descenso. Esta sobrepresión política hace que los individuos tomen conciencia de la pérdida de la lengua. Si la pérdida de la lengua es vivida traumáticamente, se producirá un incremento de la autoconciencia de dicha pérdida. Por un lado, el crecimiento de la autoconciencia de dicha pérdida producirá un crecimiento de la vertiente participativa (adhesión afectiva a la lengua como símbolo de pertenencia grupal), con lo que se refuerza el papel simbólico de la lengua 
como elemento importante para el mantenimiento de la identidad colectiva del grupo. Esta valoración simbólica de la lengua se extiende a través de los mecanismos sociales y del entramado intersubjetivo que constituyen la estructura de plausibilidad del grupo. Por otro, el uso de la lengua decrecerá menos como consecuencia del influjo de la vertiente participativa. Ésta actuará en un doble sentido: la autoconciencia de la pérdida de la lengua moverá, a los individuos que conocen la lengua, a una mayor utilización, y proporcionará mayor motivación para que aquellos que la desconocen la aprendan. También puede darse el caso, sobre todo entre aquellos individuos que no viven como problemática la pérdida de la lengua, que se abandone progresivamente su utilización, bien porque no sean conscientes del proceso de pérdida o, aun siendo conscientes, porque no se vive conflictivamente su abandono, bien porque encuentran motivaciones de tipo personal o condiciones sociales que promueven la utilización de otra lengua y la renuncia al uso de la propia (Pérez-Agote, 1986: 425; Michelena, 1977: 22).

Tres son las manifestaciones más importantes de esta toma de conciencia y de los intentos por frenar la pérdida de la lengua: la creación de ikastolas, el movimiento de alfabetización y euskaldunización de adultos, y el incremento en el número de las publicaciones en lengua vasca.

La manifestación de mayor trascendencia práctica y simbólica de la recuperación lingüística es el surgimiento de la ikastola, institución escolar encargada de la educación y la socialización de las nuevas generaciones en euskera. La ikastola pretende romper con un proceso histórico a lo largo del cual la lengua vasca había permanecido al margen del sistema educativo, convirtiéndose éste, en numerosas ocasiones, en un poderoso instrumento de represión de su utilización y de imposición del castellano.

La introducción del euskera en la escuela había recibido un cierto impulso desde los primeros años de este siglo. Pero es a partir de la década de los cincuenta cuando la transmisión del euskera a través de las ikastolas producirá profundas transformaciones en el mundo de la lengua. La ikastola va a adquirir una triple significación social: a) como referente simbólico de una cultura que atraviesa un momento de crisis de identidad; b) en tanto que codificación cultural de la identidad colectiva, y c) como reducto mítico de la identidad vasca en una situación de represión.

El euskera se había mantenido como práctica lingüística cotidiana en el ámbito de la familia y de ciertos centros de carácter eclesiástico. Al amparo de estas dos instituciones sociales, familia e Iglesia, y al margen del sistema escolar y de la vida política oficial, el euskera vehiculaba una determinada codificación de la cultura e identidad vasca, es decir, la cultura euskaldun y la identidad colectiva que hundía sus raíces en dicha cultura. Ello no quiere decir que el euskera no tuviera una gran significación, como medio de codificación cultural, en el ámbito de las relaciones sociales y en el orden político. Al contrario, como muy bien ha sabido ver J. Arpal, su existencia apuntaba «las contradicciones entre la fuerte inspiración colectiva en la lengua y la dominancia de un 
Estado moderno y de un sistema de producción y mercado que se presenta progresivamente como "erdeldun" (castellano)" (Arpal, Asua y Dávila, 1982: 39; López, 1976; Letamendía, 1975).

La crisis de la identidad colectiva es el resultado de los procesos de cambio y transformación que se producen en la estructura social de la sociedad vasca durante las décadas de los años cincuenta y sesenta. La crisis de dicha identidad es la crisis de la sociedad misma, pero, sobre todo, de la definición social de dicha identidad cultural como identidad cultural euskaldun. Esta identidad euskaldun se remitía a la estructura social de la sociedad tradicional, de la sociedad rural, donde todavía podía encontrarse la persistencia de la equivalencia entre identidad cultural y cultura euskaldun. Esta identificación entre sociedad, población y territorio euskaldunes se rompe bajo el impacto de la inmigración: «La inmigración que ya fue fijada como invasión disruptora en el nacionalismo originario, será al compás del desarrollo industrial una auténtica alteración física de la población potencialmente euskaldun. En los años sesenta las áreas euskaldunes de Guipúzcoa y Vizcaya contemplaban cómo sus núcleos urbano-industriales presentaban crecientes porcentajes de inmigración, procedentes de ámbitos ajenos a la cultura euskaldun, al mismo tiempo que se producían fuertes movilizaciones interiores, que parecían alterar sin precedentes una ecuación básica en la identidad vasca: la de población euskaldun y territorio euskaldun» (Arpal, Asua y Dávila, 1982: 44).

Será en este contexto de crisis de la identidad vasca, una vez devenga autoconsciente, cuando, paradójicamente, se plantee la necesidad de la recuperación cultural y lingüística. La ikastola, como institución que pretende la regeneración de la lengua y de la cultura vascas, se va a convertir en el referente simbólico y práctico de ambas, en un momento de crisis de la identidad vasca y en un período de negación oficial y represión institucional de cualquier manifestación que recuerde su existencia.

Uno de los indicadores más significativos de su expansión es el crecimiento que se produce, año tras año, en el número de alumnos que van a estudiar a las ikastolas. El aumento interanual ronda el 20 por 100, superando el 44 por 100 en el curso 1970-71. El incremento en el número de alumnos va acompañado por la apertura de nuevos centros. El mayor número de alumnos se concentra en la provincia de Guipúzcoa, representando el 66,7 por 100 del total. Vizcaya aporta una cantidad importante del total de alumnos (21,6 por 100), destacando el crecimiento interanual a partir del curso 1973-74. El número de estudiantes matriculados en ikastolas creció de 596 en el curso académico 1964-65 hasta $26.936 \mathrm{diez}$ años después. El número de centros también aumentó de tres en 1960 a 160 en $1975^{10}$.

${ }^{10}$ Según la investigación realizada por Arpal, Asua y Dávila, las ikastolas «aparecen en los años sesenta: a) al margen del equipamiento educativo normal, constituido por centros estatales y centros privados reconocidos; $b$ ) promovidas por grupos de padres cuyo objetivo fundamental es que sus hijos se eduquen en euskera, a pesar de las prohibiciones y represiones oficiales, que conllevan una penuria total de recursos educativos; $c$ ) en áreas industriales y urbanas (San Sebas- 
La presión política que se ejerce sobre la lengua, y cualquiera de sus manifestaciones, contribuye a que el fenómeno no quede reducido al ámbito de lo educativo y de lo lingüístico, sino que, muy al contrario, adquiera una dimensión política e ideológica que trasciende los límites del sistema educativo.

A finales de los años setenta, las ikastolas habían alcanzado una gran significación en la codificación cultural de la identidad colectiva, entroncando con la nueva definición del nacionalismo vasco y amplios sectores del nacionalismo tradicional, convirtiéndose en el «reducto mítico de la identidad vasca»: «En tanto la ikastola nacía de los euskaldunes, con sus solos medios, con posibles legitimaciones de las instituciones eclesiásticas tanto en su titularidad como en su profesorado o en las instalaciones, se presentaba como la respuesta - el reducto mítico - de la identidad vasca frente a la imposición extraña o al deterioro de las propias normas» (Arpal, Asua y Dávila, 1982: 51).

Junto al impulso de las ikastolas, dirigido a la escolarización en euskera de los más jóvenes, aparece la necesidad de alfabetizar a aquellos que conociendo la lengua vasca no pueden escribir ni leer en ella — la inmensa mayoría de dicha población, si tenemos en cuenta que el euskera había permanecido al margen del sistema escolar-y de extender su conocimiento a todos aquellos que la desconocen.

Esta iniciativa nace en 1966 bajo el patrocinio de la Real Academia de la Lengua Vasca-Euskaltzaindia. Esta promoción del euskera de contenidos lingüísticos y culturales, sin embargo, adquiere rápidamente una gran significación política que se irá desarrollando en medio de las convulsiones sociales y políticas de este período. Carecemos de datos directos que nos permitan evaluar objetivamente el esfuerzo realizado desde la segunda mitad de la década de los sesenta, pero no hay duda de su gran incidencia en la realidad social vasca, ya que convirtió en imposible cualquier intento por satisfacer el deseo expreso de aprender euskera dada la precariedad de recursos económicos y humanos. En el año 1976, J. M. Torrealday describía la situación de la siguiente manera: «La enseñanza del euskera ha adquirido ya tal amplitud y envergadura que el problema merece un tratamiento mucho más en profundidad, de acuerdo con la gravedad de la situación, de lo que lo puedan hacer algunos grupos sin medios adecuados. En el manifiesto de Durango de 1976, el grupo coordinador de Vizcaya, reconoce su importancia: dice no poder satisfacer a la demanda de la gente, cada vez más numerosa, que quiere aprender euskera; confiesa su impotencia con un montaje tan endeble y unos medios tan escasos ante la situación desbordante. Una instantánea, en 1976: 10.000 alumnos con

tián y Bilbao) en un momento de expansión característica: el crecimiento espectacular de las primeras etapas del desarrollo; $d$ ) en medios sociales tipificables como de pequeña burguesía, con fuerte identificación nacionalista vasca y frecuentes "status" de profesiones liberales, cuadros y pequeños empresarios; e) con profesorado reclutado al margen de los centros "normales" de producción-formación del profesorado (las Escuelas de Magisterio); $f$ ) centrados en la enseñanza primaria (inicialmente de seis a doce años) y en el conocimiento alfabetizado del euskera, con todas las dimensiones simbólico-ideológicas de la lengua» (Arpal, Asua y Dávila, 1982: 45). 
500 monitores. Más 5.000 en fábricas y colegios con deseos de aprender euskera. Añadamos a éstos 2.000 más que quedan en la calle por falta de locales. La solución urge. Alfabetatzen y Euskalduntzen no pueden en su estructura actual responder a la situación presente y menos a la que se avecina, por falta de medios económicos y técnicos» (Torrealday, 1977: 470-471).

Con la crisis del franquismo la calle se convierte, a través de una movilización creciente, en el espacio de expresión social y política de las reivindicaciones nacionalistas. Como ha afirmado A. Pérez-Agote, estas reivindicaciones se van haciendo progresivamente dominantes en el espacio público: «La ocupación de la calle, a pesar de su carácter intermitente, supone la apertura de un proceso por el cual los símbolos van saliendo a la superficie social: el nacionalismo se hace público y públicos se hacen los símbolos de la diferencia. Se asiste a un proceso por el cual cada vez más se expresa una conciencia mantenida hasta entonces en la privacidad. En este sentido, en la calle, en el espacio público, el nacionalismo se va haciendo dominante» (Pérez-Agote, 1987: 87).

Un símbolo a través del que se pretende recuperar la identidad colectiva largamente negada oficialmente es el euskera, y hacia él se encaminan buena parte de los esfuerzos por recomponer las señas de identidad. A ello contribuye la generalización de un sentimiento agónico de la situación en que el franquismo había dejado a la lengua. Como consecuencia, todos los intentos prácticos, que afectan al mundo de los adultos, por regenerar una situación de normalización lingüística para el euskera conducen a numerosas personas de diferentes sectores sociales a intentos de aprendizaje con diferentes grados de éxito.

La improvisación y la falta de planificación didáctica o pedagógica se pone de manifiesto en el momento que los medios de los que se dispone se muestran insuficientes para responder al crecimiento inesperado por aprender euskera. Un ex profesor responsable del movimiento de recuperación y que participó en todo este proceso lo comenta de la siguiente manera: "Desde el 77 al 79, aquella época yo la vivi como un boom, con unas inquietudes a nivel de pueblo que habia que dar una solución (...) Luego ya ves que esa inquietud no es solamente en tu pueblo, o en el pueblo de al lado, sino que va más allá, y, entonces, te metes más en temas de organización y de cómo se puede estructurar todo ese movimiento, etc., analizar la presión social. Entonces, yo creo que si habia eso en la mente de todos, pero igual lo que nos preocupaba era más el día a día, crear los materiales, buscar los profesores. Ése era un poco el tipo de preocupación que teníamos. Esto fue, yo creo, hasta el 77-78 y como hay un boom enorme, era igual atender a la demanda, provocar la demanda y atenderla, aunque casi no habia que provocarla porque los alumnos te venian como champiñones. Luego vino un bajón enorme, porque no habia calidad, porque la calidad de la enseñanza era bastante mala, la situación del profesorado muy precaria, porque no habia medios."

Si analizamos los datos recogidos en el Mapa Sociolingüístico de la Comunidad Autónoma del País Vasco elaborado a partir de los datos censales podemos obtener una imagen aproximada de la contribución de este movimiento a la recuperación de la lengua. En 1986, las personas que sin tener el euskera 
como lengua materna lo habían aprendido eran 91.546. Este número representa el 5,8 por 100 de los que tenían como lengua materna el castellano y el 17,8 por 100 del total de vascohablantes. De este grupo de nuevos vascohablantes o euskaldunberris, casi la mitad tenía menos de 17 años, lo que quiere decir que su euskaldunización se debe a las ikastolas y a la introducción del euskera en el sistema obligatorio de enseñanza. Sin embargo, más de la mitad de estos euskaldunberris habían adquirido su competencia lingüística a través de la red de euskalteguis y gaueskolas [escuelas nocturnas], que constituyen la infraestructura básica del movimiento de euskaldunización y alfabetización (Gobierno Vasco, 1989).

No parece posible atribuir dicho proceso de recuperación de la lengua a una adecuada movilización de los recursos materiales disponibles, ya que la extensión del movimiento de recuperación se produce en estos años bajo una importante penuria de recursos económicos, humanos y pedagógicos, aunque una parte de dicha recuperación se beneficia de la adhesión afectiva a la identidad colectiva que se pretendía afirmar. A pesar de ello, debemos señalar la importancia de los logros alcanzados en la recuperación de la lengua a pesar de la escasez de recursos disponibles, gracias a los recursos facilitados por las propias familias nacionalistas a las primeras ikastolas, una parte de la Iglesia católica en el mantenimiento y extensión de la producción cultural en euskera y la colaboración encontrada en amplios sectores del nacionalismo.

Sin lugar a dudas, el factor clave en la explicación de la aparición del movimiento y de su desarrollo durante los años sesenta y setenta debe situarse en la estrecha relación que durante este período se establece entre la defensa del euskera como símbolo de pertenencia a un grupo determinado y la reafirmación de la identidad colectiva vasca ${ }^{11}$. Esta relación se produce como resultado de los cambios operados en la definición de la identidad vasca, que se aleja de los postulados biológicos y se acerca a una propuesta etnocultural. Durante la década de los setenta se generalizan valores y creencias anteriormente sólo compartidos por el nacionalismo vasco, incorporando a la definición del nosotros vasco a los nuevos euskaldunes y llevando a cabo un proceso de construcción simbólica de la comunidad en la que todos tienen un lugar. La lengua adquiere una altísima centralidad simbólica (y así aparece recogido en los discursos sociales y políticos de esta época), pero no es capaz de hacer avanzar significativamente su dimensión práctica. En busca de otros factores sociales que nos ayuden a comprender la recuperación lingüística aparecen los drásticos

${ }_{11}$ Parece más sencillo analizar los factores y agentes sociales responsables del proceso de recuperación lingüística que los factores intervinientes en el proceso de decadencia del euskera y su progresiva sustitución por el castellano. Desde el punto de vista de la memoria de los actores sociales, la represión del franquismo sería el elemento fundamental, pero junto a él aparecen otros procesos de cambio social, como las migraciones, las actitudes de las élites o las propias motivaciones de los hablantes, que han influido en los procesos de cambio lingüístico. Una evaluación más detenida de estos factores está todavía por hacer, pero el lector puede encontrar una aproximación en Euskaltzaindia (1977). 
cambios que se producen en el contexto político vasco hacia finales de los setenta e inicios de los ochenta, que requieren una consideración más detallada.

\section{INSTITUCIONALIZACIÓN POLÍTICA Y PLANIFICACIÓN LINGÜÍSTICA}

Según los teóricos del enfoque de la estructura de oportunidad política, el proceso de transformación del potencial de movilización en acción depende primeramente de las oportunidades políticas. Si consideramos los cuatro aspectos variables de la estructura de oportunidad política que hemos mencionado con anterioridad, podemos afirmar que:

a) En relación con el movimiento etnolingüístico, las mayores posibilidades de participación que se abren con el establecimiento de un sistema político democrático han tenido un resultado paradójico; por un lado, ha contribuido a extender el movimiento, reforzando su papel como interlocutor de la sociedad, pero, por otro lado, ha supuesto su progresivo debilitamiento y erosión como consecuencia de la confrontación con las instituciones políticas autonómicas. Al margen de las diferentes políticas de euskaldunización que se han ido implantando en diversas esferas y sectores sociales, entre el movimiento etnolingüístico y la Administración ha existido un divorcio, ha faltado capacidad de colaboración o de trabajo en común.

b) Los cambios en las alianzas dominantes han tenido una influencia ambigua sobre la marcha del proceso de recuperación lingüística. Esta ambigüedad se debe a que las relaciones entre el movimiento etnolingüístico y los partidos políticos vienen condicionadas por la relación de éstos con el nacionalismo vasco y, por lo tanto, con la defensa de sus símbolos de identidad. Así, los vínculos entre organizaciones del movimiento y los partidos políticos son más fuertes cuanto más intensa es la defensa que éstos hacen del monolingüismo euskaldun. Por el contrario, los partidos más alejados del nacionalismo vasco mantienen unas relaciones más conflictivas o distantes con las organizaciones del movimiento etnolingüístico.

La gran fragmentación del espacio político vasco hace posible la existencia de una considerable diversidad de posturas ante el euskera. Esta diversidad se articula, básicamente, en torno a dos ejes: la aspiración a una situación de monolingüismo o de bilingüismo, y la promoción o no promoción del euskera. Más que atender a un autoposicionamiento de cada partido, uno de nuestros informantes nos presenta los resultados de una encuesta donde los actores sociales ubican a los partidos políticos de la siguiente manera: "No sé qué dirán los partidos y los movimientos adláteres, pero la gente es, desde luego, clarisimo que, por ejemplo, HB [Herri Batasuna] la sitúa en monolingüismo en euskera y en promoción del euskera; el PNV [Partido Nacionalista Vasco], EA [Eusko Alkartasuna] o EE [Euskadiko Ezkerra] estarían, si quieres, a favor del bilingüismo pero 
con promoción del euskera, no un bilingüismo conservador. Sin ninguna duda, el PSE-PSOE [Partido Socialista de Euskadi] y parte del PP [Partido Popular], lo sitúan en favor del bilingüismo pero sin promoción del euskera, mantener lo que hay y que no se mueva. Luego, [otra parte del] PP, UA [Unidad Alavesa], lo sitúa en monolingüismo en castellano y no promoción del euskera» ${ }^{12}$.

c) La división entre las élites (nacionalistas/no nacionalistas) ha influido negativamente sobre la lengua y el movimiento, al limitar el alcance de sus apoyos políticos. Mientras el movimiento etnolingüístico ha encontrado escaso apoyo entre los partidos políticos de ámbito estatal [con la excepción de Izquierda Unida], han sido los partidos nacionalistas vascos los que más cerca han estado del movimiento de recuperación lingüística, hasta el punto de que en algunos casos se ha llegado a producir una identificación entre defensa del euskera y nacionalismo vasco. Las relaciones entre las organizaciones del movimiento y $\mathrm{HB}$ han sido muy fluidas, pero no siempre han sido fáciles con otros partidos nacionalistas como PNV, EE o EA.

d) Desde el punto de vista de la disposición de aliados influyentes el resultado ha sido ambivalente. Por un lado, el apoyo de los sectores nacionalistas ha contribuido a extender la conciencia sobre la situación de la lengua; por otro lado, ha supuesto una pérdida de apoyo en aquellos sectores que no estaban de acuerdo con esta creciente identificación. Hay que tener en cuenta que una característica de la sociedad vasca durante la década de los años setenta, y buena parte de los ochenta, ha sido la existencia de una sobrepolitización, visible en numerosas manifestaciones cotidianas. A lo largo de los últimos años ese predominio de la política en la sociedad vasca ha impregnado las distintas manifestaciones de la vida social. La lengua no ha sido una excepción. Por el contrario, al ser uno de los símbolos centrales de la identidad colectiva vasca se ha convertido en objeto de disputa política. En algunos sectores de la sociedad vasca esa presencia de lo político ha estado más presente que en otros, llegando a alcanzar mayor relevancia que los planteamientos lingüísticos o culturales. En tal sentido se manifiesta este informante de EKB: "En este tema yo creo que existe un peligro, y en este momento un hecho, de que dentro de las componendas politicas que los partidos tienen que hacer para gobernar la lengua es una parcela.(...) En cuanto a partidos yo creo que el tema de la lengua es un tema conflictivo, evidentemente, $y$ es un tema que realmente suscita adhesiones y si se quiere también oposiciones. (...) Y yo creo que ha habido, por otra parte, dentro del movimiento social esta politización, este predominio de lo politico.»

12 La diversidad de posicionamientos de los partidos políticos vascos en relación con el euskera ha sido una constante a lo largo de las últimas décadas. Más allá de un supuesto consenso lingüístico, la confrontación ha estado presente en la vida política y en los debates sobre la Ley Básica de Normalización del Uso del Euskera (24 de noviembre de 1982) y, más recientemente, en los debates parlamentarios sobre el Plan General de Promoción del Uso del Euskera, donde se realiza un diagnóstico de la situación del euskera y se desarrolla un plan estratégico con medidas concretas tendentes a incrementar la transmisión, el uso social y la calidad del euskera en quince ámbitos diferentes. 
Un responsable de AEK redunda en la misma idea de la politización excesiva que existe en el mundo del euskera: "Hay una politización con respecto al euskera, de utilizar por parte de unos y de otros; por parte de unos para la legitimación institucional y por parte de otros para la deslegitimación institucional. En todo ese juego quien ha salido perdiendo ha sido precisamente el euskera y todo el proceso de concienciación social."

En referencia a los aspectos estables de la estructura de oportunidad política podemos decir que:

a) Durante el proceso de transición política a la democracia (1975-1979) y bajo la presión de una reivindicación creciente en favor de una democratización de las estructuras sociales y políticas preexistentes, las organizaciones políticas se plantean el establecimiento de un sistema político democrático que pueda dar respuesta a las demandas de autogobierno lanzadas contra el Estado desde distintas zonas del territorio español, en las que se había mantenido una identificación nacional y una conciencia particularista (Cataluña, Galicia, Euskadi), lo que venía a suponer una estructura político-administrativa distinta del Estado centralista impuesto durante el franquismo: el modelo propuesto fue el Estado de las Autonomías.

El proceso de racionalización política que se lleva a cabo tiene una doble consecuencia. A nivel estructural supone el establecimiento de una organización burocrática altamente racionalizada que controla la esfera institucional, en la que se centraliza la discusión de los asuntos que atañen a dichas instancias, lo que implica una despolitización de la vida social y de las relaciones sociales. A nivel de la conciencia, la institucionalización de la esfera política - y con ella los temas sobre los que decide- no presupone su total desaparición de la vida cotidiana, continúa siendo relevante, pero pierde su carácter público, pasando a ser un asunto privado. La política se privatiza, lo que significa que se convierte en una cuestión de elección o preferencia personal. La tesis que formularía es que estos procesos han extendido y reforzado la centralidad que el euskera ha ido adquiriendo como consecuencia del éxito del movimiento de recuperación lingüística, produciéndose, al mismo tiempo, una complejización del mundo de la lengua en torno a los siguientes ejes: pérdida del monopolio y diversificación organizativa, lo que ha permitido una situación de pluralismo en el ámbito lingüístico; la confrontación política entre AEK (movimiento etnolingüístico) y las instituciones públicas representadas en HABE; la profesionalización y/o politización de otras organizaciones en función del alejamiento o aproximación a la línea ideológica que enmarca la confrontación entre AEK-HABE, aspecto sobre el que volveré en el próximo apartado.

b) El proceso de racionalización política que ha supuesto el Estado de las Autonomías, y el consiguiente traspaso al Gobierno Vasco de las competencias contempladas en el Estatuto de Gernika, han tenido como consecuencia la paulatina puesta en funcionamiento de una Administración encargada de dar 
respuesta a las demandas que se le formulan desde la sociedad. El éxito que el movimiento de recuperación lingüística había alcanzado al extender la conciencia de la situación del euskera, y la necesidad de adoptar medidas tendentes a euskaldunizar la sociedad vasca, impulsan a las instituciones públicas a intervenir en este ámbito.

La aparición de este nuevo agente político y de su actividad han tenido como consecuencia repercusiones sociales importantes, introduciendo cambios significativos en la situación precedente y produciendo una redefinición generalizada del papel de los agentes que actúan en la esfera lingüística. Fruto de dicha actuación son las diferentes políticas linguiísticas que el Gobierno Vasco ha ido elaborando y poniendo en marcha en los diferentes niveles educativos, así como en la Administración Pública ${ }^{13}$, desde que asumió dichas competencias en el año 1980.

Los cambios en la situación lingüística pueden observarse en la tabla y el gráfico que aparecen al final de este apartado, donde se presenta la evolución de los vascohablantes de la Comunidad Autónoma del País Vasco. Entre 1981 y 1996, según los Censos de Población y los Padrones de Habitantes, el número de bilingües en la Comunidad Autónoma del País Vasco se ha incrementado en 188.660 personas, pasando del 21,5 al 30,8 por 100 del total de la población. El porcentaje de bilingües entre los mayores de 60 años viene experimentando un leve pero paulatino descenso como resultado del abandono del euskera, de los flujos de población llegada al País Vasco en las décadas de los años cincuenta y sesenta, que reducen el porcentaje de vascohablantes al incrementar el total de la población, y de la ausencia de políticas de promoción lingüística, cuando no de las políticas de desincentivación. En el grupo de los comprendidos entre 25 y 59 años se produce un ligero crecimiento de vascohablantes como consecuencia de la euskaldunización de adultos y del efecto de las primeras ikastolas (un escolar de 10 años en 1970 se encontraría ahora en medio de este grupo de población con 39 años). Pero donde realmente se puede ver con mayor claridad el impacto de las políticas lingüísticas es en el grupo de los menores de 24 años, pues mientras en 1981 únicamente el 18,7 por 100 de este grupo era bilingüe, dicho porcentaje había subido al 44,4 por 100 en 1996. Si nos fijamos en la cohorte de los comprendidos entre 5 y 9 años podemos observar que los bilingües han pasado en un período de 15 años del 20 al 57,4 por 100 . El origen de dicho incremento está en la contribución al proceso de recuperación lingüística de las ikastolas desde los años sesenta, y en la posterior introducción del euskera en el sistema obligatorio de enseñanza a partir de $1980^{14}$. Mientras la trans-

${ }^{13}$ Las políticas lingüísticas puestas en funcionamiento no se limitan al ámbito educativo (desde Pre-escolar hasta la Universidad) y a la propia Administración autonómica; también afectan a los medios de comunicación (prensa, radio y televisión), edición de todo tipo de material pedagógico, literatura, actividades culturales, de tiempo libre y de ocio, etc.

${ }^{14}$ Los escolares de la Comunidad Autónoma del País Vasco pueden optar entre tres modelos lingüísticos diferentes para seguir su educación. El modelo "A» supone recibir todas las materias 
misión familiar y la escuela eran los mecanismos fundamentales de la reproducción y extensión del euskera entre la población de menor edad, los efectos de la enseñanza a adultos (AEK, HABE, BERTAN e IKA) se dejan notar entre los de edades más avanzadas.

En relación con la situación del uso del euskera nos centraremos en tres ámbitos: la esfera familiar, la comunidad más próxima y los ámbitos formales ${ }^{15}$.

La frecuencia de utilización del euskera en la intimidad familiar se mueve entre el 48 por 100 de los que declaran que usan siempre o casi siempre el euskera en casa y el 74 por 100 que lo hacen para dirigirse a los hijos. Las otras situaciones por las que se ha interrogado a los entrevistados presentan los siguientes porcentajes: el 48 por 100 usan el euskera para hablar con sus abuelos, el 51 por 100 con su pareja, el 53 por 100 con su padre, el 56 por 100 con su madre y el 59 por 100 con sus hermanos. Tres de cada diez entrevistados manifiestan comunicarse con los familiares preferentemente en castellano.

La utilización del euskera en el ámbito laboral, de amistad y comunitario cercano sigue las mismas pautas que en el caso de la familia, aunque mostrando una presencia más reducida. Los euskaldunes hablan siempre o casi siempre en euskera con los amigos en el 50 por 100 de las situaciones, el 45 por 100 con los compañeros, el 46 por 100 con los superiores, el 48 por 100 con los comerciantes y el 78 por 100 en el mercado.

En cuanto a los espacios y situaciones cotidianas más frecuentes como ir al banco, al médico o al ayuntamiento, los vascohablantes también hacen un uso mayoritario del euskera, con excepción de las conversaciones con el médico. Tres de cada cuatro euskaldunes se comunican en euskera con el sacerdote, uno de cada dos cuando van al banco o caja de ahorros, el 59 por 100 en el ayuntamiento, el 85 por 100 con los profesores de sus hijos y sólo uno de cada tres cuando acude a un centro de salud.

del currículum escolar en lengua castellana, y estudiar la lengua vasca como una materia más. El modelo «B» contempla cursar la mitad de las materias, aproximadamente, en castellano y la otra mitad en euskera. Éste es el único modelo realmente bilingüe. En el modelo «D» los alumnos reciben todas las materias del currículum en euskera, con excepción de la materia Lengua castellana y el aprendizaje de otras lenguas que se imparten en la lengua correspondiente.

${ }_{15}$ Los datos sobre uso del euskera han sido tomados de la II Encuesta Sociolingüística de Euskal Herria 1996 (Gobierno Vasco, 1999). Para un mayor desarrollo de estos datos, así como de los factores explicativos del uso, puede consultarse Tejerina (1999). 
Evolución de los vascohablantes de la CA del País Vasco de dos y más años entre 1981 y 1996

\begin{tabular}{|c|c|c|c|c|c|c|c|c|}
\hline \multirow[b]{2}{*}{ Edad } & \multicolumn{2}{|c|}{1981} & \multicolumn{2}{|c|}{1986} & \multicolumn{2}{|c|}{1991} & \multicolumn{2}{|c|}{1996} \\
\hline & Total & $\%$ & Total & $\%$ & Total & $\%$ & Total & $\%$ \\
\hline $2-4$ & 15.913 & 14,94 & 16.513 & 22,4 & 11.651 & 21,54 & 14.998 & 31,57 \\
\hline $5-9$ & 38.064 & 20,03 & 47.091 & 28,97 & 46.368 & 40,69 & 50.197 & 57,45 \\
\hline $10-14$ & 36.231 & 19,41 & 48.210 & 26,24 & 59.510 & 37,32 & 63.610 & 55,54 \\
\hline 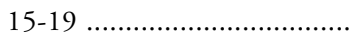 & 35.091 & 18,59 & 42.283 & 23,25 & 53.645 & 29,74 & 71.103 & 44,56 \\
\hline 20-24 .................................. & 33.007 & 19,04 & 42.949 & 23,4 & 44.266 & 25,1 & 61.324 & 34,35 \\
\hline 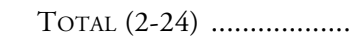 & 158.306 & 18,73 & 197.046 & 25,09 & 215.440 & 31,49 & 261.232 & 44,46 \\
\hline $25-29$ & 28.834 & 18,6 & 39.005 & 22,86 & 42.699 & 24,45 & 49.577 & 28,63 \\
\hline $30-34$ & 29.773 & 19,17 & 31.567 & 20,89 & 37.421 & 22,6 & 46.335 & 26,88 \\
\hline 35-39 & 26.628 & 18,98 & 31.740 & 21,1 & 30.426 & 20,68 & 41.582 & 25,19 \\
\hline 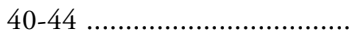 & 24.215 & 19,79 & 27.703 & 20,64 & 30.377 & 20,82 & 33.304 & 22,74 \\
\hline 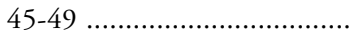 & 30.801 & 21,56 & 24.875 & 21,05 & 26.317 & 20,21 & 32.440 & 22,41 \\
\hline 50-54 & 31.867 & 24,08 & 31.352 & 22,87 & 23.665 & 20,76 & 27.699 & 21,69 \\
\hline 55-59 & 29.122 & 26,49 & 31.557 & 25,43 & 29.226 & 22,44 & 24.365 & 22,12 \\
\hline 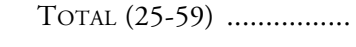 & 201.240 & 21 & 217.799 & 22,1 & 220.131 & 21,84 & 255.302 & 24,58 \\
\hline 60-64 & 24.119 & 29,8 & 28.121 & 27,92 & 29.148 & 25,13 & 29.659 & 24,02 \\
\hline $65-69$ & 21.898 & 31,8 & 22.430 & 31,23 & 25.738 & 27,77 & 28.584 & 26,43 \\
\hline 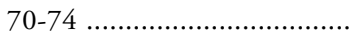 & 18.673 & 33,19 & 19.564 & 32,76 & 19.711 & 30,8 & 23.951 & 28,53 \\
\hline 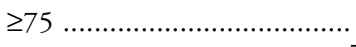 & 23.920 & 33,14 & 28.864 & 33,3 & 33.449 & 31,95 & 38.088 & 31,46 \\
\hline TOTAL $(\geq 60)$ & 88.610 & 31,85 & 98.979 & 31,04 & 108.046 & 28,63 & 120.282 & 27,55 \\
\hline TOTAL C. VASCA …........... & 448.156 & 21,53 & 513.824 & 24,58 & 543.617 & 26,27 & 636.816 & 30,87 \\
\hline
\end{tabular}

FUENTE: Elaboración propia a partir de los Censos y Padrones de 1981, 1986, 1991 y 1996. 


\section{Evolución vascohablantes 1981-1996}

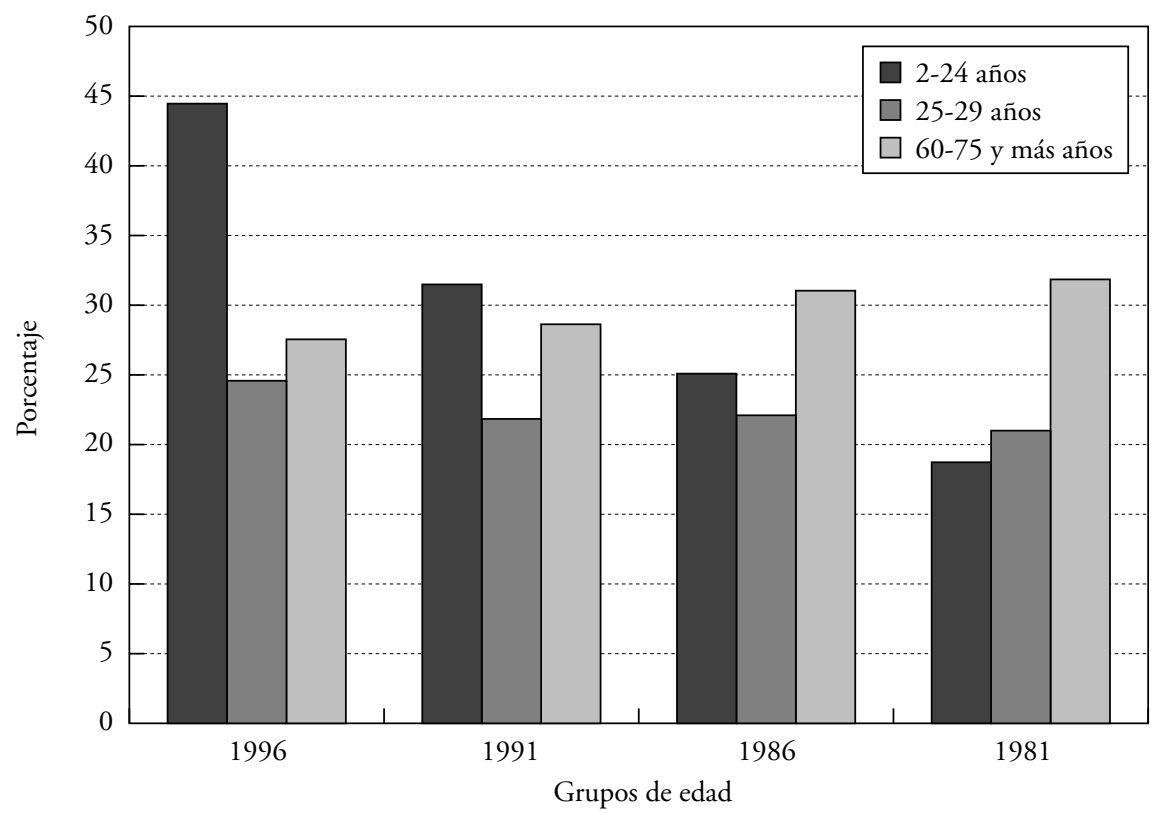

7. LA INSTITUCIONALIZACION DE LA MOVILIZACION: PLURALISMO ORGANIZATIVO Y PROFESIONALIZACIÓN DEL MOVIMIENTO

\section{a) Pluralismo organizativo}

La labor desarrollada por AEK desde finales de los años sesenta en la recuperación lingüística no había tenido, prácticamente, competencia durante muchos años, lo que ayudó a generalizar la idea de que AEK era una organización importante, central, en el área de la euskaldunización de adultos, con tendencia al exclusivismo en el protagonismo social.

Ese exclusivismo se quiebra en 1981, cuando comienza a funcionar HABE [Instituto para la Alfabetización y Euskaldunización de Adultos] como organismo autónomo dependiente del Gobierno Vasco. Las actividades de HABE, creando nuevos centros de enseñanza y financiando clases en euskera, son acciones interpretadas por AEK como una agresión contra el movimiento etnolingüístico con la pretensión de llegar a controlarlo. Esta confrontación inicial se incrementa en la segunda mitad de los años ochenta por el creciente distanciamiento ideológico entre los agentes que apoyan a HABE (Partido Nacionalista Vasco/Gobierno Vasco) y AEK (más cercano a un movimiento de masas tradicional y próximo al nacionalismo vasco radical). 
Un informante de IKA que analiza las actuaciones de AEK se manifiesta en este sentido cuando afirma que "si miramos las distintas campañas que hace AEK, las diferentes actuaciones que tiene, lo mismo con la Administración a otro nivel, nos parece que todavia siguen un poco pensando que AEK es la única solución de Euskal Herria». En el mismo sentido parece discurrir la opinión de un profesor de BERTAN para el que existe un problema de protagonismo y de reconocimiento del protagonismo: "El trabajo en común, lo que se puede entender como trabajo en común, es decir, tú respétame y yo te respeto tu propia organización, y yo aporto y tú aportas, y nos reconocemos mutuamente como que ambos estamos trabajando sin buscar el protagonismo exclusivo, eso todavia hoy aqui no ha llegado.»

A pesar de esta disputa en torno al protagonismo y el exclusivismo, lo cierto es que la capacidad de intervención y las posibilidades de actuación de las Administraciones Públicas han ido desplazando el centro de gravedad de la recuperación lingüística del ámbito del movimiento social hacia la esfera institucional. El control de los recursos humanos y materiales, y las posibilidades de diseñar escenarios futuros para intentar alcanzarlos a través de la implantación de políticas y medidas de planificación, impulsan una relación de subsidiariedad — cuando no dependencia - de las iniciativas que surgen en la sociedad civil y del movimiento de recuperación lingüística respecto de las instituciones.

Un cambio importante a nivel organizativo se produce a partir de los ochenta, cuando comienzan a aparecer una serie de asociaciones cívicas de ámbito local [Euskera Elkartea] que intentan impulsar la utilización de la lengua en todas las manifestaciones de la vida cotidiana. Estas asociaciones de carácter abierto están constituidas por jóvenes que pretenden dinamizar las actividades culturales y sociales en euskera con un doble objetivo: a) integrar y coordinar las diferentes iniciativas que surgen a nivel local, y $b$ ) incorporar en las tareas de promoción de la lengua a sectores sociales con distintas sensibilidades ideológicas.

En 1983 aparece la primera de estas asociaciones, Arrasate Euskaldun Dezagun (AED) [Euskaldunicemos Arrasate-Mondragón], convirtiéndose en poco tiempo en un ejemplo práctico rápidamente imitado en otros ayuntamientos y comarcas. Estos grupos han alcanzado una gran centralidad en el proceso de movilización lingüística, aunando la dimensión práctica de impulsar el uso del euskera y la concienciación de la situación de la lengua entre los distintos sectores sociales locales en los que trabajan. Las asociaciones que han ido apareciendo en los últimos años rondan el centenar.

\section{b) Profesionalización}

La constante expansión de la producción relacionada con la industria lingüística debido al permanente crecimiento de la demanda ha impulsado una paulatina profesionalización de las tareas relacionadas con el activismo etnolin- 
güístico. Tanto en lo relativo a la transmisión lingüística como a todas aquellas actividades que se desarrollan en torno a ella, exigen una permanente inversión de tiempo y esfuerzo en la preparación de aquellos que se mueven en este ámbito: producción de material didáctico y pedagógico, actividades complementarias como teatro, literatura, actividades de ocio y tiempo libre, etc. Muchas de las asociaciones cívicas de carácter local que hemos mencionado antes editan su propia revista, disponen de emisoras de radio y, en algunos casos, de canal de televisión. El incremento de la cualificación y profesionalización de las personas que dedican parte de su actividad a estas asociaciones es uno de sus rasgos característicos.

Asistimos a un crecimiento constante del número de personas y del volumen de recursos dedicados a la producción cultural audiovisual y de modernización de la lengua que constituye lo que podríamos denominar una nueva industria lingüística. Por supuesto que no todos los que actúan en esta industria forman parte del movimiento ni todos los activistas del mismo están abocados inexorablemente a dedicarse profesionalmente a dichas actividades. No cabe duda que las relaciones son un poco más complejas, pero tampoco podemos negar el establecimiento creciente de canales de comunicación e intercambio entre ambos que facilitan el tránsito hacia una mayor profesionalización, sobre todo si tenemos en cuenta que los beneficios potenciales suponen importantes incentivos individuales y colectivos que reducen los posibles costes.

Hasta fechas muy recientes existía una visión muy extendida sobre el hecho de que la defensa del euskera era cosa de los nacionalistas vascos. A medida que el número de vascohablantes se va incrementando y gracias a la incorporación del euskera al ámbito educativo, cada día es más frecuente encontrar personas bilingües en sectores sociales y geográficos de los que el euskera había estado tradicionalmente excluido. Estos procesos de cambio lingüístico están contribuyendo a que aquella ecuación (euskera=nacionalista) se haya roto definitivamente. Dos indicadores. Primero, la búsqueda del consenso político, ya que tanto la Ley de Normalización del Uso del Euskera como diversos planes de euskaldunización sectorial han contado con un apoyo político parlamentario superior al alcanzado en otros temas de carácter marcadamente político. Aun existiendo posturas muy diferentes entre los agentes políticos respecto del euskera, se han alcanzado importantes consensos para regular y encauzar la siempre problemática cuestión lingüística. Segundo, en la Comunidad Autónoma del País Vasco existe un apoyo mayoritario a las medidas de promoción del uso del euskera (tres de cada cuatro entrevistados) y son menos del 20 por 100 los entrevistados que manifiestan una actitud desfavorable o muy desfavorable (Gobierno Vasco, 1999) ${ }^{16}$.

${ }^{16}$ Es posible que estos indicadores se encuentren sobreponderados como resultado del ocultamiento del fenómeno de la violencia. En tal caso, la polarización social en torno a la violencia de ETA habría impedido la emergencia con mayor intensidad de otros conflictos como el lingüístico. Si la realidad fuera ésta, la progresiva o definitiva desaparición de la violencia de ETA permitiría que otras formas de conflicto se manifestaran con más frecuencia en el futuro, $y$, en 
El último indicador de la institucionalización del movimiento de recuperación lingüística remite a la progresiva ritualización de las movilizaciones en favor del euskera. Todos los años, entre primavera y otoño, las ikastolas organizan jornadas festivo-reivindicativas con una doble finalidad. Por un lado, recaudar fondos para ayudar a la ikastola organizadora. Cada provincia tiene una jornada de este tipo de manifestación. Por otro lado, estas movilizaciones tienen un carácter reivindicativo y de concienciación sobre el papel central que en el proceso de transmisión del euskera vienen desempeñando las ikastolas ${ }^{17}$.

\section{CONCLUSIONES}

La aceptación de la recuperación de la lengua como paso fundamental en el proceso de reafirmación de la identidad colectiva vasca es el resultado del éxito alcanzado por el movimiento etnolingüístico durante los últimos años del franquismo y el período de transición a la democracia. Esta reivindicación ha sido asumida por el conjunto de la sociedad vasca, aunque su defensa alcanza mayor intensidad en los sectores que se inscriben dentro del nacionalismo vasco. Si bien existe una gran pluralidad de definiciones sobre la identidad vasca, la definición de raíz etnolingüística se ha extendido en la sociedad hasta llegar a ser hegemónica. Aunque sectores alejados del nacionalismo vasco se están incorporando progresivamente a esta definición del nosotros mediante el aprendizaje de la lengua y, por lo tanto, participan en su normalización práctica y simbólica, ello no implica que terminen compartiendo los valores y creencias del nacionalismo vasco. Por el contrario, están contribuyendo a que la relación entre identidad colectiva y lengua se pueda interpretar de manera más plural. Mientras para los que se identifican con el nacionalismo vasco el euskera como atributo ocupa una centralidad tanto práctica como simbólica en la definición del nosotros, entre los no nacionalistas ambas dimensiones no van unidas: se acepta con mayor facilidad el símbolo que la práctica. Esta hegemonía de la definición esencialista comparte el protagonismo de manera creciente, con una definición de carácter más abierto, formulada en términos de ciudadanía. Son las condiciones de compatibilidad de esta pluralidad las que requerirán de una mayor investigación en el futuro.

Desde un punto de vista teórico, el enfoque de la identidad colectiva resulta clave para la comprensión del proceso seguido por el movimiento etnolingüístico vasco entre 1950 y 1975 . Durante esta etapa la existencia de un con-

tal situación, es posible que la lengua alcance un mayor protagonismo social y político como lugar de expresión de la pluralidad de la sociedad vasca.

${ }^{17}$ Las movilizaciones tienen lugar a lo largo de un día con un programa de actos folclóricos y culturales denominados Herri Urrats en el País Vasco francés, Ibilaldia en Vizcaya, Araba Euskaraz en Álava, Kilometroak en Guipúzcoa y Nafarroa Oinez en Navarra. Además, la Coordinadora de euskaltegis AEK organiza su propia fiesta y Korrika, la movilización de mayor importancia y significación social en torno al euskera. 
texto político de represión tuvo consecuencias paradójicas, pues repercutió negativamente sobre la situación de los vascohablantes, pero también desencadenó una progresiva toma de conciencia de la situación agónica de la lengua y la reaparición del movimiento de recuperación lingüística.

Con el cambio a una estructura política abierta a partir de 1975, las nuevas instituciones vascas que aparecen como resultado del proceso de descentralización del Estado y del reconocimiento de una identidad territorial propia en el País Vasco han asumido el objetivo principal del movimiento etnolingüístico, que consiste en la recuperación del euskera como símbolo de la identidad colectiva vasca.

El resultado ha sido una progresiva institucionalización del movimiento. Esta institucionalización se ha producido en un doble sentido: a) a nivel de conciencia, la relación entre recuperación de la lengua e identidad colectiva no se cuestiona seriamente en la sociedad vasca; $b$ ) a nivel estructural observamos un progresivo control institucional del movimiento etnolingüístico por su dependencia de los recursos económicos procedentes de las instituciones públicas.

Esta nueva situación ha introducido también transformaciones importantes en el interior del movimiento. Las dos más relevantes han sido: a) la aparición de un creciente pluralismo organizativo fruto tanto de los conflictos internos en AEK, la organización que fue durante largo tiempo el motor del movimiento, como de una progresiva especialización de la esfera lingüística; b) la paulatina profesionalización del movimiento etnolingüístico, que reduce la movilización y la espontaneidad e incrementa el pragmatismo y la planificación.

La relevancia de la teoría de la identidad colectiva y del proceso político para la explicación de la institucionalización del movimiento etnolingüístico se debe completar con algunos aspectos apuntados por la teoría de la movilización de recursos que nos ayudan a entender la evolución de este movimiento desde formas más clásicas de organización, con recursos escasos procedentes de la propia organización y de los activistas, hacia otras donde impera la profesionalización, con liderazgo externo, afiliación reducida y dependencia de la infraestructura e incentivos que encuentra en el conjunto de la sociedad.

\section{ABREVIATURAS}

$\begin{array}{ll}\text { AED } & \text { Arrasate Euskaldun Dezagun [Euskaldunicemos Arrasate-Mondragón]. } \\ \text { AEK } & \text { Coordinadora para la alfabetización y euskaldunización de adultos. } \\ \text { BERTAN } & \text { Asociación de centros de enseñanza de euskera. } \\ \text { EA } & \text { Eusko Alkartasuna [Alianza Vasca]. } \\ \text { EEk } & \text { Euskera Elkarteak. Asociaciones en favor del euskera. } \\ \text { EE } & \text { Euskadiko Ezkerra [Izquierda de Euskadi]. Fusionado con el PSE-PSOE. } \\ \text { EKB } & \text { Federación de asociaciones que trabajan en favor de la cultura vasca. } \\ \text { ETA } & \text { Euskadi y Libertad. }\end{array}$


Instituto de Alfabetización y Euskaldunización de Adultos, dependiente del Gobierno Vasco.

HB Herri Batasuna [Unidad Popular].

IKA Asociación de centros de enseñanza de euskera.

IKASTOLA Centro educativo que enseña en euskera.

IU-EB Izquierda Unida. Coalición de partidos de izquierda.

PNV-EAJ Partido Nacionalista Vasco.

PP Partido Popular.

PSE-EE/PSOE Partido Socialista de Euskadi.

$\mathrm{UA}$

Unidad Alavesa.

\section{REFERENCIAS}

Arana Golri, Sabino (1965): Obras Completas, Buenos Aires, Sabindiar Batza.

ARANZADI, Juan (1981): El milenarismo vasco, Madrid, Taurus.

Arpal, J.; Asua, B., y DÁvila, P. (1982): Educación y sociedad en el País Vasco, San Sebastián, Txertoa.

BARTH, F. (1976): Los grupos étnicos y sus fronteras, FCE, México.

COHEN, Anthony P. (1985): The symbolic construction of community, London, Routledge.

CODOL, Jean-Paul (1981): «Une approche cognitive du sentiment d'identité», Information sur les Sciences Sociales, 20, 1.

CORCUERA, Javier (1979): Orígenes, ideología y organización del nacionalismo vasco (1876-1904), Madrid, Siglo XXI.

DiAnI, Mario (1992): «The concept of social movement», The Sociological Review, 40.

EISENSTADT, S. N. (1969): «El Estado, la Sociedad y la formación de Centros. Algunos problemas en la evolución de la Sociología Política», Revista Española de la Opinión Pública, núm. 18 (octubre-diciembre).

ElorZA, Antonio (1978): Ideologías del nacionalismo vasco 1876-1937 (De los «euskaros» a Jagi Jagi), San Sebastián, L. Aramburu Editor.

ERIKSON, Erik H. (1966): «The concept of identity in race relations: Notes and queries», Daedalus, 95.

EUSKALTZAINDIA (1977): El libro blanco del euskera, Bilbao, Euskaltzaindia.

Eustat (1984): Educación y euskara. Padrón Municipal de Habitantes 1981 de la CA de Euskadi, Bilbao, Gobierno Vasco.

- (1988): Educación y euskara. Padrón Municipal de Habitantes 1986 de la CA de Euskadi, Vitoria-Gasteiz, Gobierno Vasco.

- (1994): Educación y euskara. Censos de Población y Viviendas 1991 de la CA de Euskadi, Vitoria-Gasteiz, Gobierno Vasco.

FIsHman, Joshua A. (1989): Language and Ethnicity in Minority Sociolinguistic Perspective, Clevedon (Philadelphia), Multilingual Matters.

Garmendia, Jose María (1979): Historia de ETA, San Sebastián, Haranburu.

Gobierno Vasco (1989): Mapa Sociolingüistico. Análisis demolingüistico de la CAV derivado del Padrón de 1986, Vitoria-Gasteiz, Secretaría General de Política Lingüística.

- (1995): La Continuidad del Euskera, Vitoria-Gasteiz, Servicio Central de Publicaciones del Gobierno Vasco.

- (1999): II Encuesta sociolingüistica de Euskal Herria 1996. La Continuidad del Euskera II, Vitoria-Gasteiz, Servicio Central de Publicaciones del Gobierno Vasco.

Guiot, Jean M. (1977): «Attribution and identity construction: some comments», American Sociological Review, 42 (octubre).

Gumperz, John J. (1982): Language and Social Identity, Cambridge, Cambridge University Press. 
Gurruchaga, Ander (1985): El código nacionalista vasco durante el franquismo, Barcelona, Anthropos.

Hobsbawn, Eric, y Ranger, Terence (eds.) (1983): The Invention of Tradition, Cambridge, Cambridge University Press.

IBARRA, Pedro (1989): La evolución estratégica de ETA, Donostia, Kriselu.

JÁuregui, Gurutz (1981): Ideología y estrategia política de ETA. Análisis de su evolución entre 1959 y 1968, Madrid, Siglo XXI.

Jenkins, J. Craig (1983): «Resource Mobilization Theory and the Study of Social Movements», Annual Review of Sociology, 9, pp. 527-553. [Edición española de 1994 en Zona Abierta, 69, pp. 5-49.]

JUARISTI, Jon (1987): El linaje de Aitor. La invención de la tradición vasca, Madrid, Taurus.

KASTERSZTEIN, Joseph (1981): "Aspects psychosociaux de l'identité», Information sur les Sciences Sociales, 20, 1.

KoHn, Hans (1984): Historia del nacionalismo, México, FCE.

Letamendía, Francisco [Ortzi] (1975): Historia de Euskadi. El nacionalismo vasco y ETA, Francia, Ruedo Ibérico.

LÓPEZ ADÁN, Emilio [Beltza] (1976): El nacionalismo vasco 1876-1936, San Sebastián, Txertoa.

- (1977): El nacionalismo vasco en el exilio (1837-1960), San Sebastián, Txertoa.

MeluccI, Alberto (1996): Challenging codes. Collective action in the information age, Cambridge, Cambridge University Press.

McADam, Doug (1982): Political Process and the Development of Black Insurgency, 1930-1970, Chicago, The University of Chicago Press.

MCCARThY, John D., y ZALD, Mayer N. (1977): "Resource Mobilization and Social Movements: A Partial Theory», American Journal of Sociology, 82, pp. 1212-1241.

MichelenA, Luis (1977): «El largo y difícil camino del euskera», en Euskaltzaindia, El libro blanco del euskera, Bilbao, Euskaltzaindia.

Pérez-Agote, Alfonso (1986): "The role of religion in the definition of a symbolic conflict. Religion and the Basque problem», Social Compass, XXXIII/4.

- (1987): El nacionalismo vasco a la salida del franquismo, Madrid, CIS/Siglo XXI.

SARASOLA, Ibon (1976): Historia social de la literatura vasca, Madrid, Akal.

Sarrailh de Ihartza, F. (1963): Vasconia. Estudio dialéctico de una nacionalidad, Buenos Aires.

SHILS, Edward A. (1961): "Center and periphery», en The Logic of Personal Knowledge. Essays presented to Michael Polanyi, Londres.

SMITH, Anthony D. (1991): National identity, London, Penguin [hay traducción castellana].

SOlOZÁBAL, J. J. (1975): El primer nacionalismo vasco, Guadalajara, Tucar.

TABOADA-LEONETTI, Isabelle (1981): «Identité individuelle, identité collective», Information sur les Science Sociales, 20, 1.

TAJFEL, Henri (1974): «Social identity and intergroup behaviour», Social Science Information, 13, 2.

Tarrow, Sidney (1994): Power in Movement. Social Movements, Collective Action and Politics, Cambridge, Cambridge University Press [hay traducción castellana en Alianza Editorial].

Tejerina, Benjamín (1992): Nacionalismo y lengua. Los procesos de cambio lingüistico en el País Vasco, Madrid, CIS/Siglo XXI.

- (1999): «Euskera», en Panorámica Social de Euskadi, Vitoria-Gasteiz, Gobierno Vasco [en prensa].

Tejerina, B.; Fernández Sobrado, J. M., y Aierdi, X. (1995): Sociedad civil, protesta y movimientos sociales en el País Vasco, Vitoria-Gasteiz, Servicio Central de Publicaciones del Gobierno Vasco.

TORrealday, J. M. (1977): Euskal idazleak gaur. Historia social de la lengua y literatura vascas, Oñate-Arantzazu, Jakin.

VAlLE, Teresa del (1988): Korrika. Rituales de la lengua en el espacio, Barcelona, Anthropos.

WeIner, Richard (1982): "Collective identity formation and social movements», Psychology and Social Theory, 3 (primavera-verano).

ZALD, Mayer N., y MCCARTHY, John D. (1987): Social Movements in an Organizational Society: Collected Essays, New Jersey, Transaction Publishers. 


\begin{abstract}
This paper sets out to develop the notion that any attempt at explaining what is taking places in the Basque Country today in terms of linguistic recovery can only be understood by linking it with the ongoing construction of the collective Basque identity. The crystallisation of this growing link between language and identity attests to the central role of the ethno-linguistic movement. The author of this paper develops his arguments in five sections. He begins by the expounding on the various theoretical contributions to the construction of the collective identity and the dominant focuses in the analysis of social mobilisation. He then goes on to examine more recent historical precedents relative to the collective Basque identity and the contexts in which their contents are being transformed. The third section looks at the consequences for the Basque language and collective identity of the linguistic recovery movement of the 1960s and 1970s. In the fourth section, the author analyses the influence of the political changes which took place in the 1980s and the progressive institutionalisation of the Basque collective identity on the linguistic movement and status. Finally, he examines the transformations which have marked the linguistic recovery movement in recent years as a result of the changes which have taken place in Basque society.
\end{abstract}

